\title{
Lactate and Pyruvate Catabolism in Acetic Acid Bacteria
}

\author{
By J. DE LEY AND J. SCHELL \\ Laboratory for Microbiology, State University, Gent, Belgium
}

(Received 10 January 1962)

\begin{abstract}
SUMMARY
The enzymic mechanism of D- and L-lactate catabolism was the same in several strains of Acetobacter and Gluconobacter. This was taken to indicate a close relationship between these groups. Both isomers were broken down by way of pyruvate and acetaldehyde to acetate. Identical reactions were carried out by two sets of enzymes of a different nature and localization, one particulate, the other soluble. All strains contained a constitutive, soluble pyruvate decarboxylase which required thiamine pyrophosphate and $\mathrm{Mg}^{++}$. When grown on lactate, a pyruvate decarboxylase was also present in the particulate fraction. No evidence was found for a pyruvate oxidase system. Acetaldehyde was oxidized by a particulate oxidase system and by NADP- and NAD-linked dehydrogenases. This last enzyme was activated by coenzyme $A$ and glutathione. The particulate pyruvate decarboxylase was not very tightly bound to the particles, as it could easily be detached by washing with buffer. The oxidase systems could not be removed under these conditions.
\end{abstract}

\section{INTRODUCTION}

The 'acetic acid bacteria' are divided into the polarly flagellate Gluconobacter (also called Acetomonas) and the peritrichous Acetobacter (Leifson, 1954; Shimwell, 1958; De Ley, 1961). In spite of this morphological difference both biotypes show many physiological and biochemical similarities, indicating a close relationship. It seemed that an investigation of the comparative metabolism of pyruvate in these bacteria might offer further possibilities in exploring their taxonomic relationship, since three different mechanisms for pyruvate catabolism have been reported. A direct pyruvate decarboxylase was described for G. suboxydans (King \& Cheldelin, 1954) and for $A$. peroxydans (De Ley \& Schell, 1959). A pyruvate oxidase system was reported for $A$. pasteurianus (King, Kawasaki \& Cheldelin, 1956) and $A$. liquefaciens (Stouthamer, 1960). According to Rao (1955) in $A$. aceti acetaldehyde was not an intermediate in pyruvate breakdown, nor did lipoic acid play a role. In previous studies (De Ley \& Schell, 1959) we have established that subcellular particles from $A$. peroxydans oxidized D- and L-lactate, pyruvate and ethanol with oxygen as terminal electron acceptor. The particles contained pyruvate decarboxylase and a cytochrome system, and no additional co-factors were required. The reactions are summarized in the following diagram:

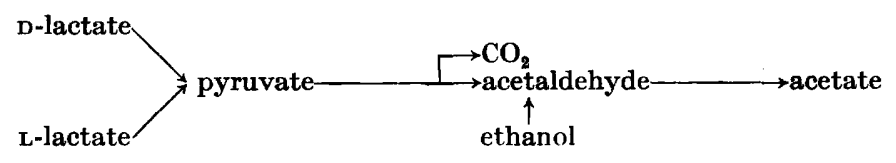


An identical reaction sequence occurred in the cytoplasm, but with enzymes of a different nature. The soluble $\mathrm{D}$ - and L-lactate dehydrogenases required the addition of artificial electron acceptors to demonstrate their activity. The oxidation of ethanol required either NAD or NADP and acetaldehyde dehydrogenase was NADPlinked.

The present paper is concerned with a study of the metabolism of lactate and pyruvate by other 'acetic acid bacteria'.

The following abbreviations will be used: CoA coenzyme A; GSH, reduced glutathione; ThPP, thiamine pyrophosphate; NAD, nicotinamide-adenine dinucleotide; NADP, nicotinamide-adenine dinucleotide phosphate; $\mathrm{NADH}_{2}$, reduced nicotinamide-adenine dinucleotide; $\mathrm{NADPH}_{2}$, reduced nicotinamide-adenine dinucleotide phosphate.

\section{METHODS}

Organisms. The origin of the strains used was described previously. We shall adhere here to the nomenclature of strains previously proposed by De Ley (1961). The following strains were investigated: Acetobacter aceti strain $\mathrm{Ch} 31, A$. aceti (rancens) strain 23, A. aceti (pasteurianus) strain 11, A. aceti (turbidans) NCIB 6424, $A$. aceti (xylinum) strain $25, A$. aceti (liquefaciens) strain 20 (this strain has previously tentatively been classified as a Gluconobacter, due to the uncertainty of its flagellation; recent investigation of its infrared spectrum (A. W. Scopes, personal communication) showed that it belongs in the biotype Acetobacter), Gluconobacter oxydans (suboxydans, strain 26; G. oxydans (melanogenus) NCIB 8086. Other strains of our collection were occasionally used. When received the strains were examined for purity by plating and their diagnostic characteristics redetermined. During the course of the investigation the purity and homogeneity of the strains was occasionally checked by plating.

Growth of organisms. Strains aceti $\mathrm{Ch} \mathbf{3 1}$, rancens $\mathbf{2 3}$ and xylinum 25 were grown in the following lactate medium: $\mathrm{M} / 120 \mathrm{KH}_{2} \mathrm{PO}_{4}, \mathrm{M} / 120 \mathrm{Na}_{2} \mathrm{HPO}_{4}, 0.2 \%$ yeast extract (Difco), $0.2 \% \mathrm{NH}_{4} \mathrm{Cl}, 0.025 \% \mathrm{MgSO}_{4} .7 \mathrm{H}_{2} \mathrm{O}, 2 \%$ ammonium DL-lactate and $0.02 \mathrm{mg} . \%$ bromocresolpurple, $\mathrm{pH} \mathrm{6.5}$. The organisms were grown and harvested as previously described (De Ley \& Schell, 1959). Strain pasteurianus 11 did not noticeably grow on this medium, in spite of the fact that lactate was consumed. Therefore this strain, as well as aceti $\mathrm{Ch} 31$, rancens 23, turbidans 6424, suboxydans 26 and melanogenus 8086 were grown on a glycerol medium, which had the same composition as above, except that $2 \%$ glycerol was substituted for DL-lactate. Other strains were grown in Roux flasks on solid media containing $1 \%$ yeast extract (Difco), $5 \%$ glucose, $3 \%$ calcium carbonate and $2.5 \%$ agar. After growth the bacteriological purity of the suspensions was checked by the following four methods : (1) microscopic appearance of the cells; (2) Gram negativity; (3) inability to grow on $0.5 \%$ peptone- $0.25 \%$ yeast extract; and (4) the typical oxygen uptake in the Warburg apparatus with selected substrates as mentioned previously (Schell, 1960 ; Joubert, Bayens \& De Ley, 1961).

Enzyme preparations. The cells were disrupted and the soluble and particulate fractions prepared as previously described (De Ley \& Schell, 1959).

Enzyme activity. The conventional Warburg apparatus was used as previously described, as were the methods for the determination of NAD- and NADP-linked 
dehydrogenases, for the detection of pyruvate decarboxylase and of the cytochromes, and for the preparation of $\mathrm{CO}$ and mixtures of $\mathrm{N}_{2} / \mathrm{O}_{2}$ (De Ley \& Schell, 1959).

\section{RESULTS}

\section{Comparative enzymology of lactate catabolism}

An identical mechanism of lactate catabolism was found in all the strains investigated. As this system was nearly the same as the one already described for Acetobacter aceti (peroxydans) (De Ley \& Schell, 1959) it may suffice to summarize the results briefly.

Oxidations by resting cells

With all the strains of the suboxydans group of Frateur (1950) 1 mole $\mathrm{O}_{2} /$ mole lactate, 1 mole $\mathrm{O}_{2} /$ mole ethanol and 0.5 mole $\mathrm{O}_{2} /$ mole pyruvate or acetaldehyde was consumed. With all the other strains the above substrates were almost completely oxidized to $\mathrm{CO}_{2}$ and $\mathrm{H}_{2} \mathrm{O}$. With most of the strains D-lactate was oxidized faster than L-lactate. Addition of $10^{-2} \mathbf{M}$-arsenite resulted in a complete inhibition of the oxygen uptake beyond the acetate stage. Direct observation with a Beck-Hartridge reversion spectroscope showed thatall the above substrates reduced the cytochromes.

\section{Enzymes in the particulate fraction}

One mole $\mathrm{O}_{2} /$ mole of either D- or L-lactate, 1 mole $\mathrm{O}_{2} /$ mole ethanol, 0.5 mole $\mathrm{O}_{2} /$ mole pyruvate or acetaldehyde was taken up. The pH optimum was 5-6. D-lactate was again oxidized faster than the L-isomer. Addition of cofactors (NAD, NADP, FAD, FMN or riboflavin) or artificial carriers (methylene blue or $N$-methyl phenazinium methosulphate) was not required or did not stimulate the oxidation. Oxygen uptake was inhibited $75 \%$ by mixtures of $90 \% \mathrm{CO}$ and $10 \% \mathrm{O}_{2}$ and completely by $10^{-3} \mathrm{M}-\mathrm{KCN}$. $\mathrm{NADH}_{2}$ was readily oxidized but acetate was not oxidized.

\section{Soluble enzymes}

In the absence of an artificial carrier no oxygen was taken up. In the presence of methylene blue or N-methyl phenazinium methosulphate, the same overall oxidations took place as with the particulate fraction. D-Lactate was again oxidized faster than the L-isomer. Addition of cofactors did not stimulate the reaction. In the presence of either $\mathrm{M} / 640 p$-benzoquinone, $0 \cdot 1 \mathrm{M}$-dimedon or $3 \cdot 10^{-2} \mathrm{M}-\mathrm{NaHSO}_{3}$, the reaction stopped after an oxygen uptake of $0.5 \mathrm{~mole} /$ mole lactate indicating the formation of pyruvate or acetaldehyde. Neither an NAD- nor an NADPlinked dehydrogenase for either substrate could be detected.

\section{Mechanism of pyruvate catabolism}

Here only the results obtained with strain aceti $\mathrm{Ch} 31$ are described, since essentially the same situation was encountered in all the other strains. As the activity of the 'pyruvate oxidase system' depends on the substrate on which the cells have been grown, the results reported in this section were all obtained with cells grown on a glycerol medium as described under 'Methods'. 


\section{Pyruvate decarboxylase}

In all the strains the soluble fraction effected a strong direct decarboxylation of pyruvate, which was completely inhibited by $\mathrm{M} / 640 \mathrm{p}$-benzoquinone and stimulated by either $8 \mathrm{mg}$. dimedon $/ \mathrm{ml}$. or $3 \cdot 10^{-2} \mathrm{M}-\mathrm{NaHSO}_{3}$, indicating the formation of acetaldehyde as reaction product. After removal of the cofactors by dialysis against $0.6 \%$ versene, addition of $\mathrm{Mg}^{++}$and $\mathrm{ThPP}$ was required for the decarboxylation (Fig. 1).

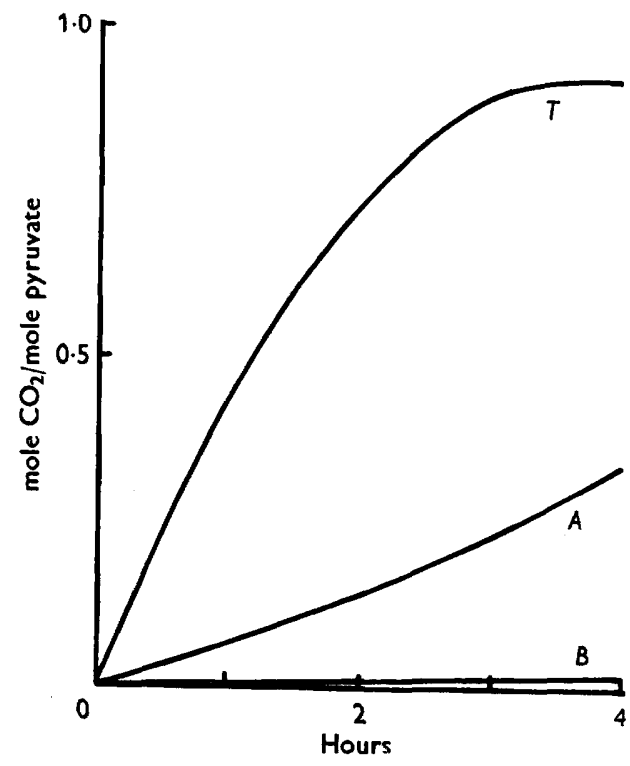

Fig. 1

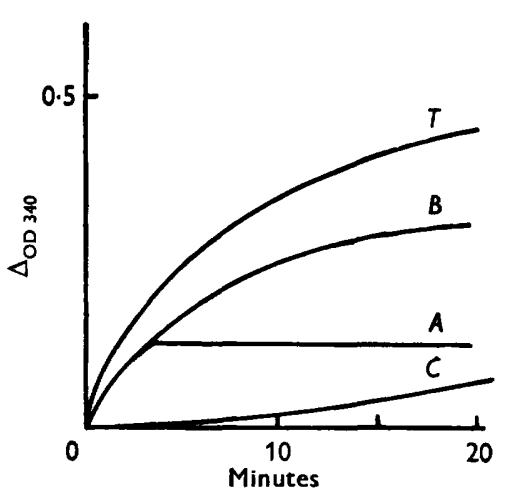

Fig. 2

Fig. 1. Requirement for thiamine pyrophosphate and $\mathrm{Mg}^{++}$of the soluble pyruvate decarboxylase of Acetobacter aceti (rancens). The soluble enzyme preparation had been dialysed against $0.6 \%$ versene in $0.02 \mathrm{~m}$-phosphate buffer $\mathrm{pH} 7 \cdot 4$, overnight at $4^{\circ}$. $\mathrm{CO}_{2}$ production was measured in the conventional Warburg apparatus at $30^{\circ}$ in $\mathrm{N}_{2}$ atmosphere. Curve T, $1 \mathrm{ml}$. soluble enzyme, $5 \mu$ mole $\mathrm{MgCl}_{2}, 500 \mu \mathrm{g}$. ThPP and $10 \mu$ moles sodium pyruvate. Curve $A, \mathrm{Mg}^{++}$absent. Curve $B$, ThPP absent.

Fig. 2. The oxidation of acetaldehyde with NAD by crude extract of glycerol-grown Acetobacter aceti, strain Ch 31. Curve T, 1 ml. crude extract, $200 \mu$ moles tris buffer pH 9 , $10 \mu$ moles KCN, $0.4 \mu$ mole CoA, $5 \mu$ moles $\mathrm{MgCl}_{2}$, $10 \mu$ moles glutathione, $0.3 \mu$ mole NAD and $10 \mu$ moles acetaldehyde. Curve $A, 1 \mathrm{ml}$. crude extract, $200 \mu$ moles tris buffer $\mathrm{pH} 9$, $10 \mu$ moles acetaldehyde. Curve $B$, same as curve $A$ but $10 \mu$ moles KCN added. Curve $C$, same as curve $B$, but $10^{-2} \mathrm{~m}$-arsenite added. Final volume, always $3 \mathrm{ml}$. The formation of $\mathrm{NADH}_{2}$ was measured in the Beckman spectrophotometer, model DU and expressed as the increase in O.D. at $340 \mathrm{~m} \mu$.

\section{Acetaldehyde dehydrogenases}

Both crude extract and soluble fraction contained an NAD-linked acetaldehyde dehydrogenase. This enzyme is stimulated by $\mathrm{CoA}$ or glutathione and completely inhibited by $10^{-2} \mathrm{M}$-arsenite (Fig. 2). $\mathrm{KCN}$ and the alkaline $\mathrm{pH}$ inhibited the strong $\mathrm{NaDH}_{2}$-oxidase. The effect of $\mathrm{CoA}$ and glutathione became even more pronounced after dialysis. The soluble enzyme preparation was dialysed overnight 
against a suspension of Dowex $50\left(\mathrm{H}^{+}\right)$. The stimulation by $\mathrm{CoA}$ and glutathione is illustrated in Fig. 3. A very active NADP-linked acetaldehyde dehydrogenase was also present (Fig. 4). From the negligible activation by KCN and the complete reduction of NADP, it was concluded that no $\mathrm{NADPH}_{2}$-oxidase was present. The NADP- and NAD-linked acetaldehyde dehydrogenases were different enzymes, since the latter was completely inhibited by $10^{-2} \mathrm{M}$-arsenite, whereas the former was not (Fig. 5a,b). Dimedon did not inhibit the reaction with NADP, whereas

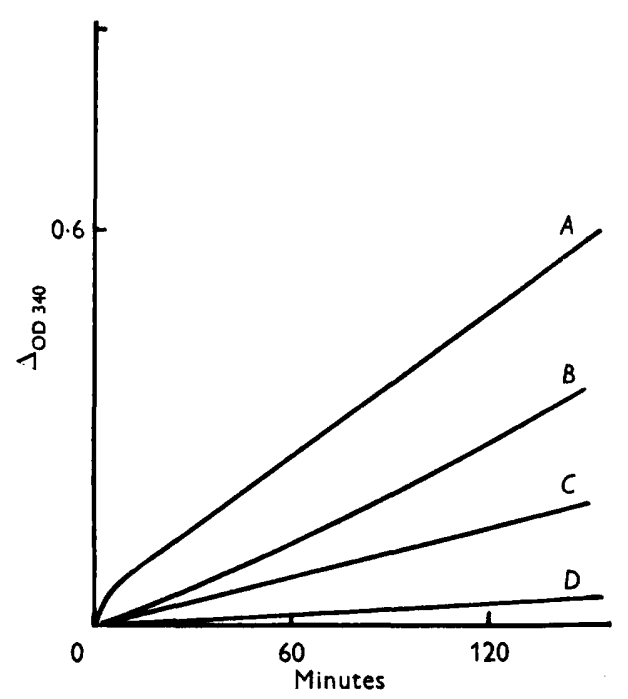

Fig. 3

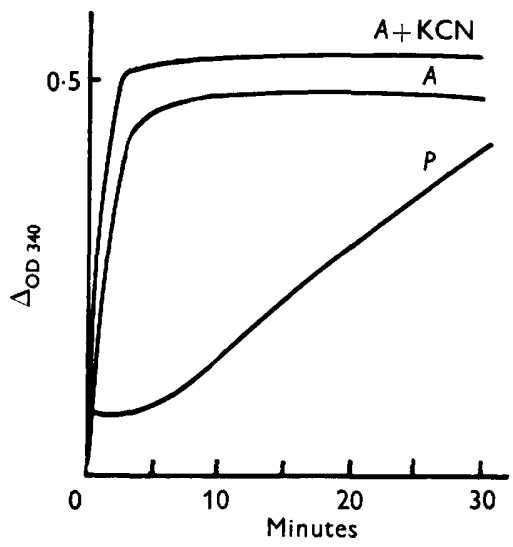

Fig. 4

Fig. 3. Effect of CoA and glutathione on the oxidation of acetaldehyde by NAD with a dialysed preparation of soluble enzymes of glycerol-grown Acetobacter aceti, strain Ch 31. Same conditions as in Fig. 2, but without KCN. Curve $A$, complete system. Curve $B, \mathrm{CoA}$ absent. Curve $C$, glutathione absent. Curve $D$, both $\operatorname{CoA}$ and glutathione absent. The results are expressed as in Fig. 2.

Fig. 4. Oxidation of acetaldehyde and pyruvate in the presence of NADP and crude extracts of Acetobacter aceti, strain Ch 31. Curve $A, 1 \mathrm{ml}$. crude extract, $10 \mu$ moles acetaldehyde, $0.3 \mu$ moles NADP; final volume $3 \mathrm{ml}$. M/45 phosphate buffer $\mathrm{pH} 7$. Curve $A+\mathrm{KCN}$, same as for curve $A$, but $10 \mu$ moles KCN added. Curve $P$, same as curve $A$ but pyruvate instead of acetaldehyde. The results are expressed as in Fig. 2.

a marked inhibition was observed with NAD. This might be because the NADPlinked enzyme was very active, resulting in a rapid formation of $\mathrm{NADH}_{2}$, before acetaldehyde reacted with dimedon. In the case of the less active NAD-linked dehydrogenase, there might be a competition between the enzyme and dimedon for acetaldehyde. The enzyme itself was not inhibited by dimedon, as seen from the initial reaction rates.

\section{The 'pyruvate oxidase system'}

According to King et al. (1956), cells of Acetobacter pasteurianus, grown on a medium with $2 \%$ glycerol, contained a pyruvic oxidase system, requiring CoA, glutathione, ThPP and NAD. We fully confirmed this observation with extracts of 
glycerol-grown cells (Fig. 6). $\mathrm{KCN}$ and the alkaline $\mathrm{pH}$ inhibited the strong $\mathrm{NADH}_{2}$ oxidase. Although pyruvic decarboxylase itself was partially inhibited at this $\mathrm{pH}$, the results showed that the reaction was activated by CoA and GSH. They seemed to indicate the existence of a pyruvate oxidase system. On the other hand an alternative explanation might as well be that the reduction of NAD with pyruvate was not due to a pyruvate oxidase system, but to the joint action of pyruvate decarboxylase and the NAD-linked acetaldehyde dehydrogenase. The experiments shown in Fig. 7 supported this view. At higher NAD concentrations acetaldehyde was dehydrogenated at once, whereas pyruvate was oxidized after a marked induction

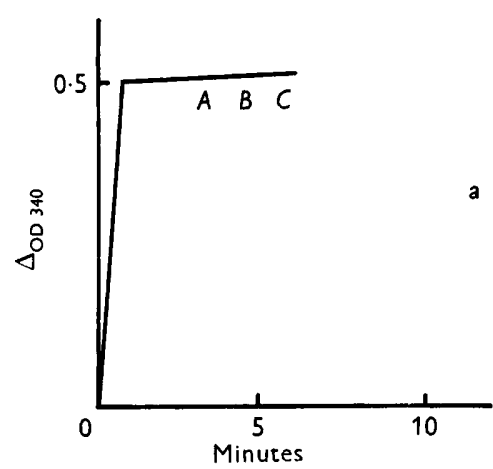

Acetaldehyde NADP

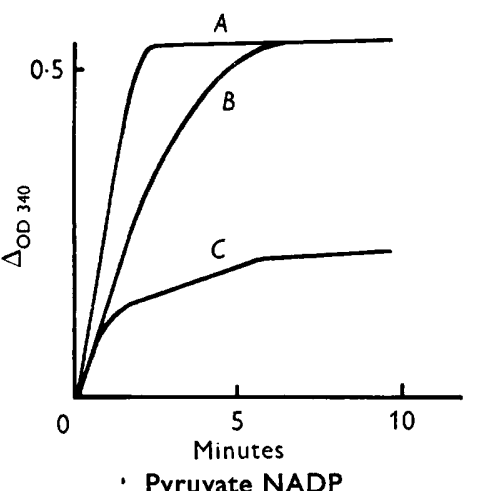

- Pyruvate NADP

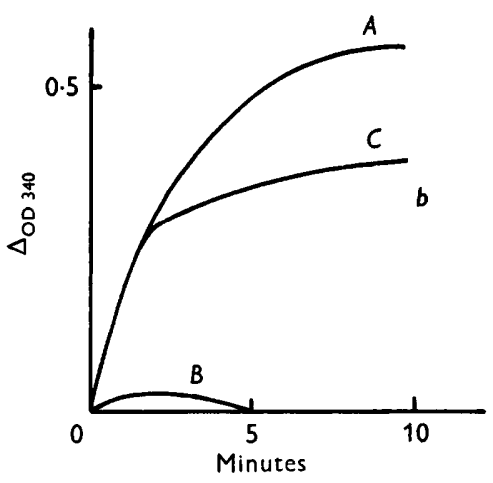

Acetaldehyde NAD

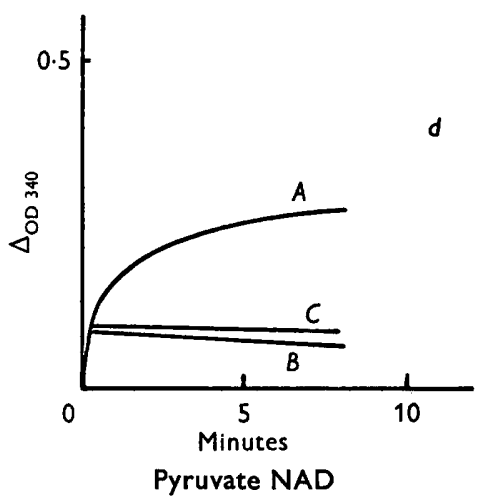

Fig. 5. Effect of dimedon and arsenite on the oxidation of acetaldehyde and pyruvate by NADP and NAD with soluble enzymes of glycerol-grown Acetobacter aceti, strain Ch 31. $a$ and $b$, acetaldehyde as substrate. $c$ and $d$, pyruvate as substrate. Curve $A$, no inhibitors. Curve $B, 10^{-2} \mathrm{M}$-arsenite as inhibitor. Curve $C, 8 \mathrm{mg} . / \mathrm{ml}$. dimedon as inhibitor. With NAD the basic systems contained $1.5 \mathrm{ml}$. enzyme preparation, $200 \mu \mathrm{moles}$ tris buffer pH 8.2, $0.3 \mu$ moles NAD, $10 \mu$ moles of either acetaldehyde or pyruvate. Final volume $3 \mathrm{ml}$. With NADP, $1.5 \mathrm{ml}$. enzyme preparation, $M / 45$ phosphate buffer pH $7 \cdot 0,0 \cdot 3 \mu$ mole NADP, $10 \mu$ moles substrate in $3 \mathrm{ml}$.

period. Addition of $10 \mu$ moles of $\mathrm{MgCl}_{2}$ resulted in an appreciable shortening of the induction period. Other evidence is illustrated in Fig. 5. Dimedon inhibited NAD reduction by pyruvate almost completely and $\mathrm{NADPH}_{2}$ formation quite markedly. Arsenite again hardly affected $\mathrm{NADPH}_{2}$ formation and blocked $\mathrm{NADH}_{2}$ formation. The results of Fig. 5 and 7 indicated that acetaldehyde was an intermediate in the 
pyruvate oxidation and that a pyruvic oxidase system was not involved. It seemed possible that acetyl-CoA was involved according to the following pathway:

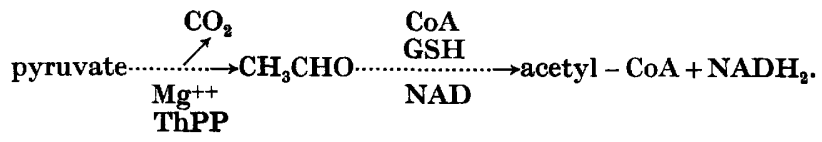

Therefore the formation of acetyl-CoA was tested by the method of Lipmann \& Tuttle (1945) in the system described by Kitos, King \& Cheldelin (1957). However, acetyl-CoA was not detected, even when the experiments were repeated on several occasions with several modifications.

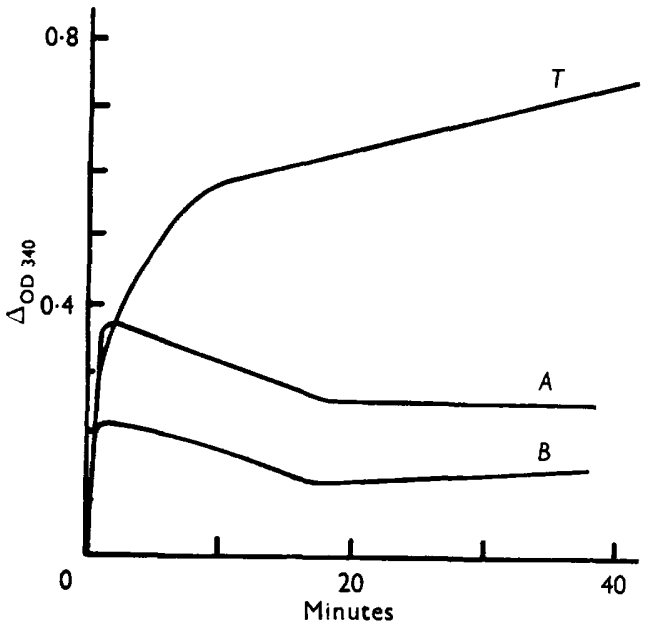

Fig. 6

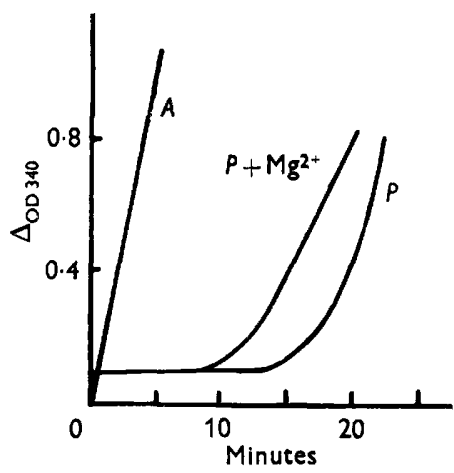

Fig. 7

Fig. 6. Apparent presence of a pyruvic oxidase system in extracts of Acetobacter aceti, strain Ch 31. Mixture: $1 \mathrm{ml}$. of crude extract, $200 \mu$ moles tris buffer $\mathbf{p H ~} 9,10 \mu$ moles $\mathrm{KCN}, 0 \cdot 4 \mu$ moles CoA, $5 \mu$ moles $\mathrm{MgCl}_{2}, 10 \mu$ moles glutathione, $0 \cdot 3 \mu$ mole $\mathrm{NAD}, 500 \mu \mathrm{g}$. ThPP and $10 \mu$ moles sodium pyruvate. Final volume $3 \mathrm{ml}$. Curve $T$, complete system. Curve $A, \operatorname{CoA}$ absent. Curve $B$, both $\operatorname{CoA}$ and glutathione absent. The results are expressed as in Fig. 2.

Fig. 7. Oxidation of acetaldehyde and pyruvate in the presence of high NAD concentrations with crude extracts of Acetobacter aceti, strain Ch 31 . Curve $A, 0 \cdot 6 \mathrm{ml}$. extract, $3 \mu$ moles NAD, $10 \mu$ moles acetaldehyde, $200 \mu$ moles tris buffer pH 9 . Final volume $3 \mathrm{ml}$. Curve $P$, same system but pyruvate instead of acetaldehyde. Curve $P+$ $\mathrm{Mg}^{++}$same system as for curve $\boldsymbol{P}$, but $10 \mu$ moles $\mathrm{MgCl}_{2}$ added. The results are expressed as in Fig. 2.

It is noticeable that the enzyme system for the formation of $\mathrm{NADH}_{2}$ from pyruvate is dependent on the substrate on which the cells have been grown. With extracts from cells, grown on the lactate medium, no formation of $\mathrm{NADH}_{2}$ could be observed, not even in a complex system containing $50 \mu \mathrm{g}$. CoA, $500 \mu \mathrm{g}$. ThPP, $10 \mu$ moles GSH, $5 \mu$ moles $\mathrm{MgCl}_{2}, 5 \mu$ moles $\mathrm{MnCl}_{2}, 10 \mu \mathrm{g}$. lipoic acid, $10 \mu$ moles $\mathrm{Na}_{2} \mathrm{HPO}_{4}$, $0.3 \mu$ mole NAD, $10 \mu$ moles pyruvate, $0.3 \mathrm{ml}$. crude extract or soluble enzyme and $200 \mu$ moles tris buffer pH 8.0. 


\section{Localization of the pyruvate decarboxylase}

We shall now show that the localization of the pyruvate decarboxylase depends on the carbon source on which the cells had been grown and that the particulate enzyme is not bound in the same way as are the oxidase systems.

Resting cells of the strains aceti $\mathrm{Ch} 31$, rancens 23 and xylinum 25 oxidized several substrates in a different way, depending whether they had been grown on either lactate or glycerol (Fig. 8). With lactate-grown cells, ethanol, D-lactate and acetate were oxidized completely to $\mathrm{CO}_{2}$ and water. In the presence of $10^{-2} \mathrm{M}$ arsenite only 1 mole $\mathrm{O}_{2}$ per mole ethanol or D-lactate was taken up, while acetate was not oxidized at all (Fig. 8a). With cells grown on glycerol (Fig. $8 b$ ) the result
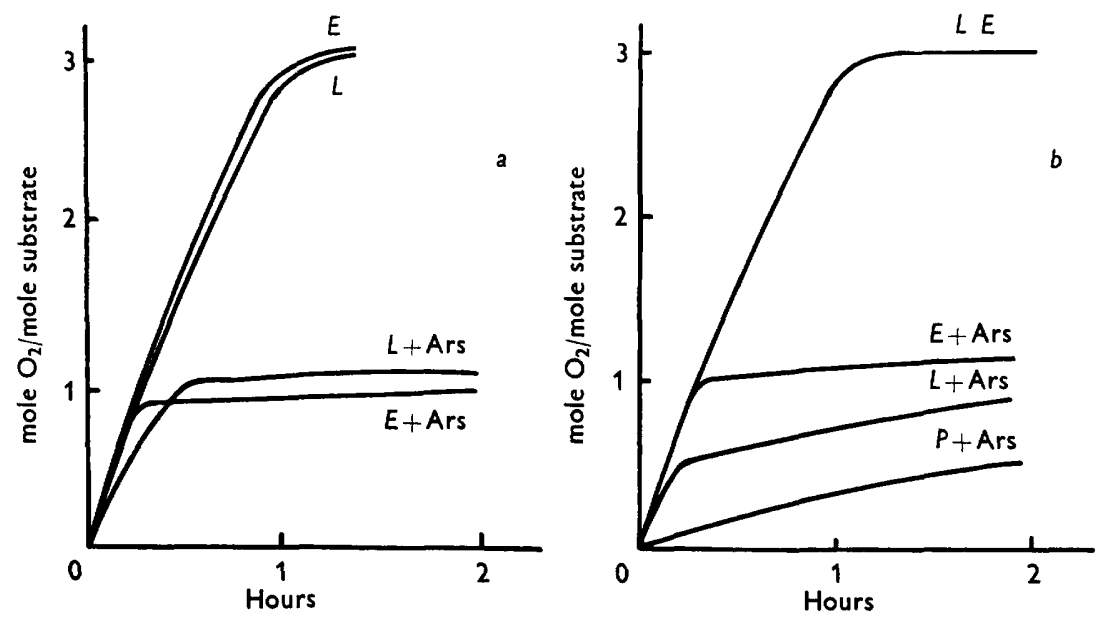

Fig. 8. Effect of $10^{-2} \mathrm{M}$-arsenite on the oxidation of ethanol and sodium D-lactate by resting cells of Acetobacter aceti, strain Ch 31. $a$, Cells grown on DL-lactate. $b$, Cells grown on glycerol. The oxygen uptake was measured in the conventional Warburg apparatus at $30^{\circ}$. Each vessel contained $80 \mathrm{mg}$. of living bacteria (wet weight) in a final volume of $3 \mathrm{ml}$. Side arm $10 \mu$ moles substrate. $0.1 \mathrm{ml} .20 \% \mathrm{KOH}$ in central well. Curves $E$, ethanol. Curves $L$, sodium D-lactate. Curves $L+$ Ars, D-lactate and arsenite. Curves $\boldsymbol{E}+$ Ars, ethanol and arsenite. Curve $\boldsymbol{P}+$ Ars, pyruvate and arsenite.

was the same except for the oxidation of $\mathrm{D}$-lactate in the presence of arsenite, where only 0.5 mole $\mathrm{O}_{2}$ was taken up. Presumably either pyruvate or acetaldehyde had been formed. Pyruvate itself was not oxidized under these conditions. No pyruvate decarboxylase activity could be demonstrated in the particulate fraction prepared from the strains aceti $\mathrm{Ch} 31$, rancens 23, pasteurianus 11 and suboxydans 26, grown on either glycerol or ethanol, while particles from lactate-grown cells of the strains peroxydans 8618 , aceti $\mathrm{Ch} 31$, rancens 23 and xylinum 25 contained pyruvate decarboxylase activity. The particulate fractions always contained active systems oxidizing lactate, ethanol and acetaldehyde. These facts might be explained if one accepts that the pyruvate decarboxylase was associated with the cytoplasmic membrane only when the cells are grown on a substrate in whose catabolism pyruvate is an intermediate e.g. lactate. When grown on another substrate, e.g. glycerol or ethanol, the decarboxylase would be present only in the cytoplasm. The observation 
by Stouthamer (1960), that particles from glucose-grown Acetobacter aceti (liquefaciens) displayed no pyruvate decarboxylase activity, fits in with this hypothesis.

The particulate pyruvate decarboxylase displayed another peculiarity, in that it could easily be dislodged from the particles by simple washing with buffer. The particles were separated from the crude extract by centrifugation in the Spinco Centrifuge model $\mathrm{L}$ at $100,000 \mathrm{~g}$ for $2 \mathrm{hr}$. The supernatant was carefully decanted and the tube wiped dry. The gel-like material was suspended in $\mathrm{m} / 50$ phosphate buffer $\mathrm{pH} 6 \cdot 5$. An aliquot was used for the estimation of the decarboxylase activity
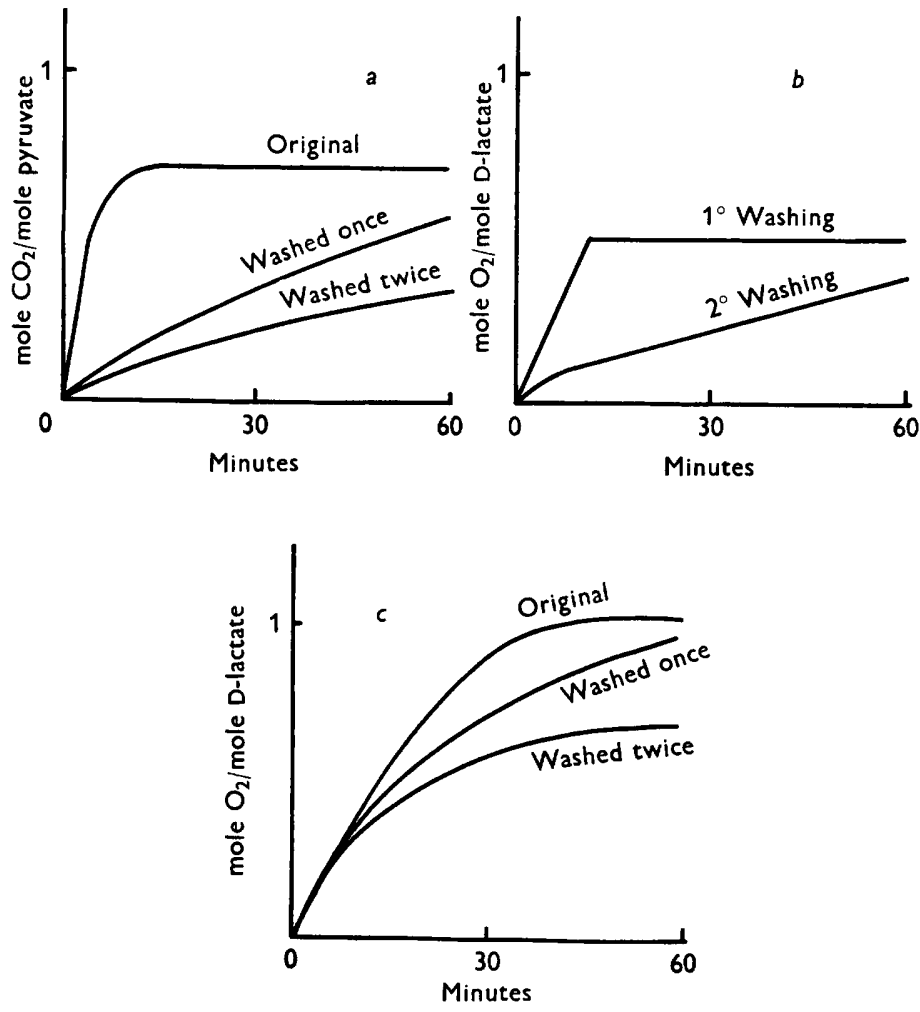

Fig. 9. Release of pyruvate decarboxylase from the particulate fraction by washing with buffer. $a$, Pyruvate decarboxylase activity in the particulate fraction of disrupted $A$. aceti, strain $\mathrm{Ch}$ 31, before washing and after first and second washing with $\mathrm{M} / 50$ phosphate buffer $\mathrm{pH} 6 \cdot 5$. $b$, Decarboxylase activity in the supernatant after washing and centrifugation. Enzyme activity was determined in the conventional Warburg apparatus at $30^{\circ}$ in $\mathrm{N}_{2}$ atmosphere. $c$, Release of D-lactate oxidase system from the particulate fraction in the same conditions as in $a$. Enzyme activity was determined in the Warburg respirometer.

(Fig. 9a). The remainder was again centrifuged at $100,000 \mathrm{~g}$ for $2 \mathrm{hr}$. The pellet was taken up in the same buffer and the activity redetermined. About $75 \%$ had been lost. A third treatment resulted in a further $10 \%$ loss of activity. That no cofactor had been washed out but the entire enzyme itself could be shown because the supernatant now contained the activity (Fig. $9 b$ ). This experiment in itself was of course not a proof that the enzyme was dislodged from the particles, as it could very well have been a mere washing away of the enzyme from the soluble 
fraction, which was undoubtedly still trapped between the mass of centrifuged particles in the first pellet. That this was not the case was shown by the study of the behaviour of a typical soluble enzyme during the washing procedure: the lactate dehydrogenase. For activity measurements the latter enzyme was coupled to $N$-methyl phenazinium methosulphate. In the first washings already there was hardly any activity, while the second time there was no activity whatsoever. This showed that the soluble pyruvate decarboxylase, which was trapped between the particles after the first centrifugation, was negligible as compared to the amount of enzyme released during washing. In contrast to pyruvate decarboxylase, the other particulate enzymes were hardly dislodged. This is illustrated for the D-lactate oxidizing enzyme system (Fig. 9c), where the initial rate of oxidation was hardly affected by washing. In this case the final oxygen uptake decreased from 1 to 0.5 mole $\mathrm{O}_{2} /$ mole substrate, because the pyruvate decarboxylase had been washed off.

\section{DISCUSSION}

\section{Mechanism and localization of lactate catabolism as an argument for phylogenetic unity in the acetic acid bacteria}

The enzymic mechanism for the breakdown of lactate is essentially identical in all the strains of Acetobacter and Gluconobacter investigated. This extends our previous results obtained with $A$. aceti (peroxydans) (De Ley \& Schell, 1959) and shows that the latter were only one example of a general phenomenon. In acetic acid bacteria both isomers of lactate and ethanol are metabolized to acetate by two sets of enzymes, which carry out the same overall reactions and pass by the same intermediates, but are of a different nature and localization. There is first the particulate system which oxidizes both $\mathrm{D}$ - and L-lactate by way of pyruvate and acetaldehyde to acetate and oxidizes ethanol by way of acetaldehyde likewise to acetic acid. From previous experiments (De Ley \& Dochy, 1960a, 1960 b) it is known that the enzymically active particles are fragments of the cytoplasmic membrane which were called 'oxidosomes' (De Ley, 1960). The membrane also contains most of the cytochromes, which serve as the electron-accepting system in the oxidations. The nature and the coenzymes of the particulate dehydrogenases for lactate, ethanol and acetaldehyde (as well as for many other substrates upon which we reported on other occasions) remain unknown. It may be remembered that neither NAD, NADP, FMN, FAD, riboflavin, nor methylene blue, phenazine methosulphate and 2,6-dichlorophenol indophenol ever showed any stimulation with the particulate fraction.

The soluble enzymes in the cytoplasm have been extensively discussed in the above paper, which need not be repeated here. From the present investigations it follows that there are only a few quantitative differences between the strains which are of minor importance such as (1) the ratio between the rates of oxidation of $\mathrm{D}$ - and L-lactate is not the same for all the strains, although $\mathrm{D}$-lactate is oxidized always at least as fast as L-lactate; (2) the inhibition by $\mathrm{H}_{2} \mathrm{O}_{2}$ of the oxygen uptake by the oxidosomes is more pronounced in $A$. aceti (peroxydans) than in the other strains, but this is due to the very active peroxidases in peroxydans (De Ley \& Vervloet, 1961) and the absence of catalase in this strain. It thus appears that the enzymic mechanism for the breakdown of lactate and ethanol to acetate is a common 
and basic feature of all the acetic acid bacteria, since the same system with the same distribution in the cell is found in such widely divergent strains as $A$. acet $i$ (peroxydans) and Gluconobacter oxydans (suboxydans). It is an important argument in favour of the phylogenetic unity of these bacteria as previously postulated (De Ley, 1961).

\section{Mechanism of pyruvate catabolism}

A survey of the literature had revealed that three different mechanisms of pyruvate breakdown appeared to be operative in acetic acid bacteria. This raised a promising question of comparative biochemistry, but it proved to be deceiving. Indeed, a pyruvate decarboxylase was found in all strains investigated. At a first glance there was also a pyruvic oxidase, since we could easily repeat the experiments of King et al. (1956), in which reduction of NAD by pyruvate required CoA, glutathione and ThPP. However, upon closer inspection, a different explanation becomes apparent. We have indeed shown that the same extracts contain an NADlinked acetaldehyde dehydrogenase which is activated by CoA and glutathione and completely inhibited by $10^{-2} \mathrm{M}$-arsenite. Furthermore, the inhibition by dimedon shows that pyruvate reduces both NAD and NADP only after decarboxylation to acetaldehyde.

The hypothesis of a separate pyruvate oxidase system is unnecessary as the reduction of the nicotinamide nucleotides can be explained by the joint action of pyruvic decarboxylase (requiring ThPP) and an NADP- or NAD-linked acetaldehyde dehydrogenase (the last being activated by $\mathrm{CoA}$ and glutathione and being inhibited by arsenite). It is worth noticing that the apoenzymes for both coenzymes are different, since the NADP-linked enzyme is not inhibited by arsenite and not activated by CoA and glutathione. In addition, the NAD-linked enzyme seems to be semi-inducible, since no or doubtful activity was found in lactate-grown cells. Neither could we find evidence for the contention of Rao $(1955,1957)$ that Acetobacter aceti contains an arsenite- and dimedon-insensitive pyruvate catabolic pathway, which does not include pyruvate decarboxylase. We invariably found the latter enzyme and the influence of both inhibitors has been mentioned above. Closer inspection of Rao's results reveals that his system was apparently arsenite insensitive because glutathione was added for the preparation of the cell extracts and dimedon indeed inhibited pyruvate oxidation $33 \%$. The overall conclusion is thus that a pyruvate decarboxylase could be demonstrated convincingly in all the strains investigated.

It may be noted that resting cells appear to metabolize acetaldehyde by way of the NAD-linked enzyme and not by the more active NADP-linked one, as can be seen from the inhibition of the lactate oxidation by arsenite.

\section{The localization of the pyruvate decarboxylase}

All strains of acetic acid bacteria investigated so far contain pyruvate decarboxylase in the cytoplasm. Whether the cytoplasmic membrane will bear a decarboxylase depends on the substrate on which the cells are growing. Only the particles from lactate-grown cells displayed pyruvate decarboxylase activity. On the other hand, particles from cells grown on glycerol, ethanol or glucose never showed any activity of the latter enzyme. It seems that, when the enzyme plays an active role during 
the growth of the bacteria, it is associated with the cytoplasmic membrane. The physiological role of this 'inducible' localization can be seen from experiments with resting cells. When the pyruvate decarboxylase is associated with the cytoplasmic membrane, lactate is oxidized to acetate completely by way of the membranelinked system. In the other case lactate is metabolized by the membrane only as far as pyruvate, which then enters the cytoplasm and is broken down by the soluble decarboxylase. This is illustrated in Fig. 10.

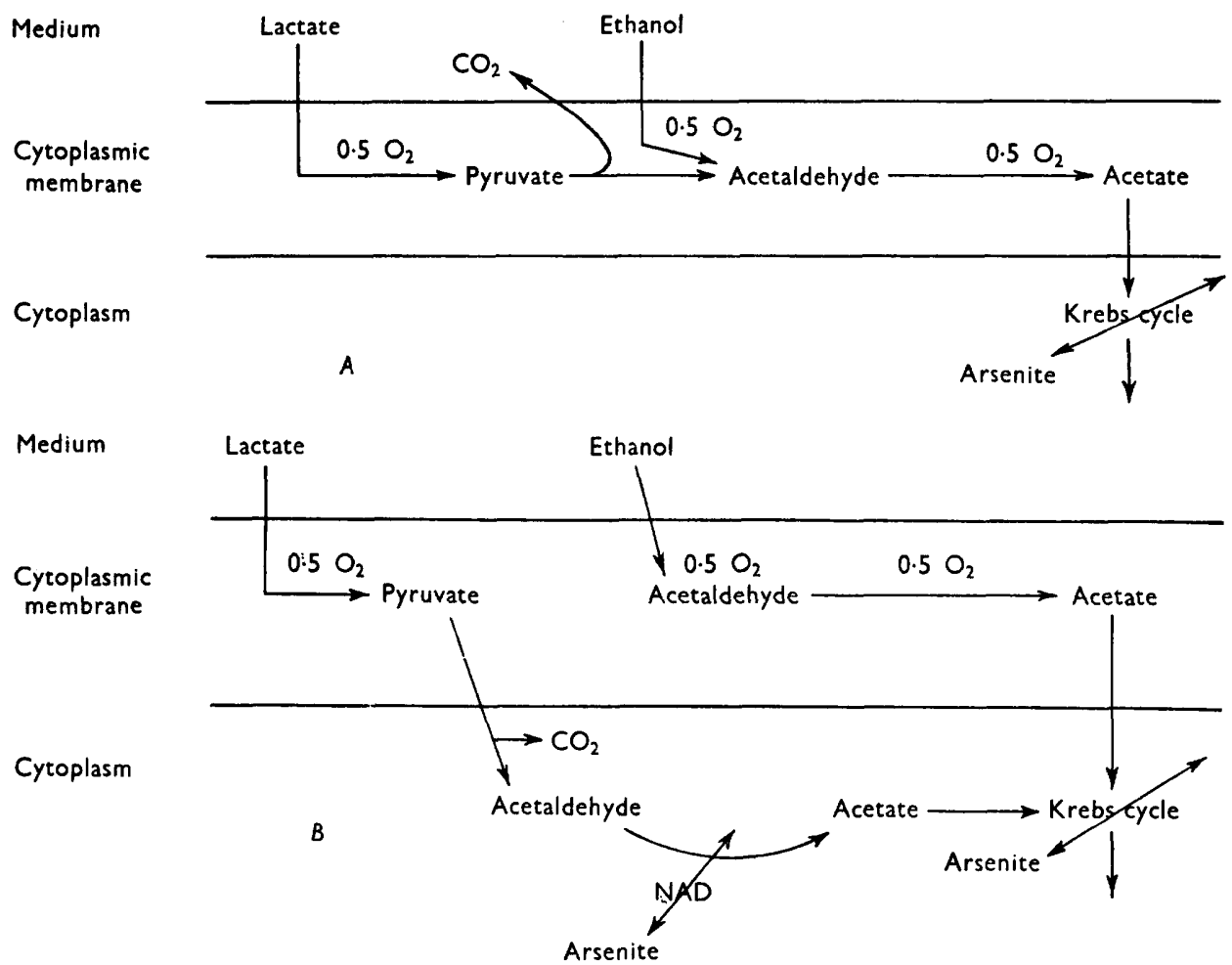

Fig. 10. Localization of the main pathway of lactate metabolism in acetic acid bacteria, grown on different substrates. $A$, cells grown on lactate; $B$, cells grown on either glycerol, ethanol or glucose.

It seems thus to be of importance for the cells that their substrates are metabolized as much as possible by a chain of enzymes which are located closely together.

The particulate pyruvate decarboxylase demonstrates a second peculiarity residing in its mode of linkage. It could indeed be washed off the particles by repeated treatment with buffer. We have not yet encountered a similar behaviour with other particulate enzymes of these bacteria, which are always tightly bound. Nothing is known of the mode of linkage of pyruvate decarboxylase to the particulate material, neither can it be stated whether the particulate enzyme is the same as the soluble one (with an inducible localization) or if they are different ones (with an inducible particulate enzyme). 
Both authors are indebted to the Nationaal Fonds voor Wetenschappelijk Onderzoek : the senior one for a grant, J.S. as Aangesteld Navorser.

\section{REFERENCES}

De Ley, J. (1960). 'Oxidosomes' in bacterial anatomy. Nature, Lond. 188, 831.

De LEY, J. (1961). Comparative carbohydrate metabolism and a proposal for a phylogenetic relationship of the acetic acid bacteria. J. gen. Microbiol. 24, 31.

DE LEY, J. \& DOCHY, R. (1960a). On the localisation of oxidase systems in Acetobacter cells. Biochim. biophys. Acta, 40, 277.

De Ley, J. \& Dochy, R. (1960b). Intermittent ultrasonic disruption and localisation of enzymes in acetic acid bacteria. Biochim. biophys. Acta, $42,538$.

De Ley, J. \& Schell, J. (1959). Studies on the metabolism of Acetobacter peroxydans. II. The enzymic mechanism of lactate metabolism. Biochim. biophys. Acta, 35, 154.

DE Ley, J. \& Vervloet, V. (1961). Studies on the metabolism of Acetobacter peroxydans. III. Some properties and localisation of peroxidases. Biochim. biophys. Acta, 50, 1.

Frateur, J. (1950). Essai sur la systématique des Acétobacters. Cellule, 53, 285.

Joubert, J. J., BAYENS, W. \& DE LEY, J. (1961). The catabolism of aminoacids by acetic acid bacteria. Antonie van Leeurvenhoek J. Microbiol. Serol. 27, 151.

King, T. E. \& Cheldelin, V. H. (1954). Pyruvic carboxylase of Acetobacter suboxydans. J. biol. Chem. 208, 821.

King, T. E., Kawasaki, E. H. \& Cheldelin, V. H. (1956). Tricarboxylic acid cycle activity in Acetobacter pasteurianus. J. Bact. 72, 418.

Krtos, P. A., King, T. E. \& Cheldelin, V. H. (1957). Metabolism of fructose-1-6-diphosphate and acetate in Acetobacter suboxydans. J. Bact. 74, 565.

Leifson, E. (1954). The flagellation and taxonomy of species of Acetobacter. Antonie van Leeuwenhoek J. Microbiol. Serol. 20, 102.

Lipmann, F. \& Tuttle, L. C. (1945). A specific method for the determination of acyl phosphates. J. biol. Chem. 159, 21.

RAO, M. R. R. (1955). Pyruvate and acetate metabolism in Acetobacter aceti and A. suboxydans. Thesis, University of Illinois, Urbana, Ill., U.S.A.

RAo, M. R. R. (1957). Acetic acid bacteria. Annu. Rev. Microbiol. 11, 317.

Scheld, J. (1960). Vergelijkende biochemische, physiologische en phylogenetische study van azijnzuurbacteriên. Thesis, University of Gent.

Shimwell, J. L. (1958). Flagellation and taxonomy of Acetobacter and Acetomonas. Antonie van Leeutvenhoek J. Microbiol. Serol. 24, 187.

Stouthamer, A. H. (1960). Koolhydraatstofwisseling van de azijnzunrbacteriën. Thesis, University of Utrecht. 